\title{
PULL-OUT BEHAVIOR OF CFRP SINGLE-STRAP GROUND ANCHORS
}

\author{
Haifeng Fan, Anastasios P. Vassilopoulos and Thomas Keller \\ Composite Construction Laboratory (CCLab), École Polytechnique Fédérale de Lausanne \\ (EPFL),Station 16, Bâtiment BP, CH-1015 Lausanne, Switzerland \\ Email: thomas.keller@epfl.ch, Web Page: http://www.cclab.ch
}

Keywords: carbon fiber-reinforced polymer, ground anchors, strap, confinement

\begin{abstract}
Pull-out experiments were performed on four carbon fiber-reinforced polymer (CFRP) ground anchors simulating their applications in rock and soil. The CFRP tendons used in these anchors comprise a single-strap end on both the ground and air sides. On the ground side, the single-strap end is embedded in a cylinder of high-strength grout which fits into the borehole. In rock applications, the ground-side anchor can be used directly without additional confinement, while in the case of soil, an additional CFRP confinement ring is needed to prevent premature failure in the strap region. The load transfer from the strap to the grout cylinder occurs progressively; approximately $50 \%$ of the load is transferred at the semicircular strap end while the remaining 50\% are transferred at the curved transition from the strap to the rod geometry of the free length.
\end{abstract}

\section{Introduction}

Prestressed and permanent ground anchors made of steel are widely used for the stabilization of structures in civil engineering, such as slopes, dams, tunnels and bridge foundations Ground anchors usually consist of an air-side anchor head and a tendon which - after a free length - is anchored into the soil or rock media. One of their earliest applications was the strengthening of Cheurfas dam in Algeria in 1934 [1]. However, the components of conventional steel anchors are generally vulnerable to galvanic corrosion. Instead of solving the durability problem with expensive and not, in any case, reliable protection systems, replacing steel by corrosion-resistant carbon fiber reinforced polymers (CFRP) has evolved as an alternative solution [2].

Conceptually similar to steel tendons, mechanical or bonded anchors are usually used for FRP materials [3]. However, carbon fibers are strongly anisotropic, exhibiting much lower properties in the transverse fiber direction, which may lead to a premature failure at the anchoring area due to high shear and through-thickness stress concentrations. A simpler and much more material-tailored anchoring method, which does not mimic the anchorage technique of steel anchors, are CFRP straps, where the CFRP tension elements can be easily anchored using steel pins $[4,5]$. This anchorage method has already been used to strengthen existing reinforced concrete flat slabs against punching [6], timber roof structures [7] and masonry structures [8]. However, no research has yet been conducted on the anchoring of strap ends of ground anchors in a soil or rock media.

In this paper, a new application of the strap anchorage method for prestressed and permanent CFRP ground anchors, with a capacity of more than $1000 \mathrm{kN}$, is presented. The CFRP tendon comprises a multi-strap end on the ground side, anchored in the borehole, and a single-strap anchor head on the air side, see Fig. 1. The multi-strap end is embedded in a high-strength grout cylinder, which is confined by CFRP rings at the locations of strap curvatures. The confinement rings have two functions: a) increase the compressive strength of the grout cylinder at the strap end locations; b) deviate the spreading forces - occurring at the strap ends and at the transition from the straps' to the straight tendon geometry - into the cylinder's axial direction. The grout cylinder is thus stepwise axially loaded by the axial components of the spreading forces. The prefabricated $20-80 \mathrm{~m}$-long tendons can 
be coiled and then transported to the construction site, inserted into the borehole, anchored by injecting fresh grout and finally prestressed to $60 \%$ of the design load.

In a first stage, a CFRP ground anchor with a single-strap end on the ground side was developed, which however can already be used in soil and rock media where only smaller loads need to be transmitted. The anchor capacity was determined in pull-out experiments. The influence of different confinement levels and CFRP ring arrangements on the load-bearing behavior of the anchor was investigated.

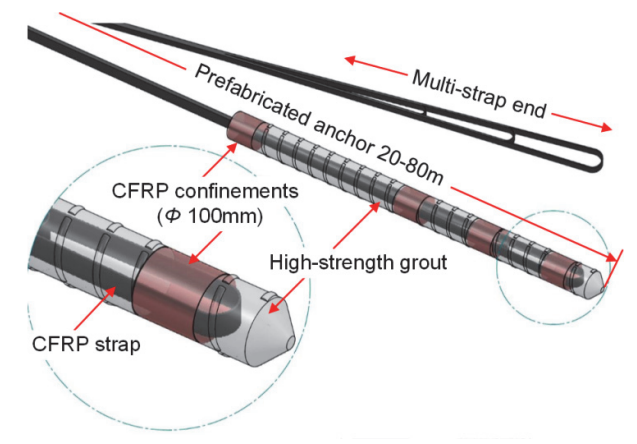

Fig. 1. Prestressed and permanent CFRP ground anchors with multi-strap end

\section{Experimental program}

\subsection{CFRP single-strap anchor specimens}

The CFRP single-strap tendons used in this study were produced by Carbo-Link, Fehraltorf (Switzerland); the dimensions are shown in Fig. 2. The tendons were composed of unidirectional UTS50 F24 24k 1600tex D carbon fibers impregnated with XB 3515 epoxy resin; the fiber volume fraction was $60 \pm 2 \%$.

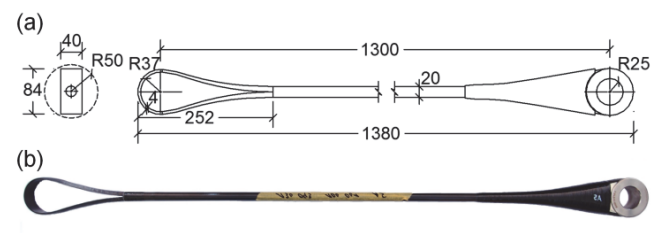

Fig. 2. CFRP single-strap tendon specimen (without grout cylinder on left ground side), (a) dimensions in [mm] (not to scale), (b) photo

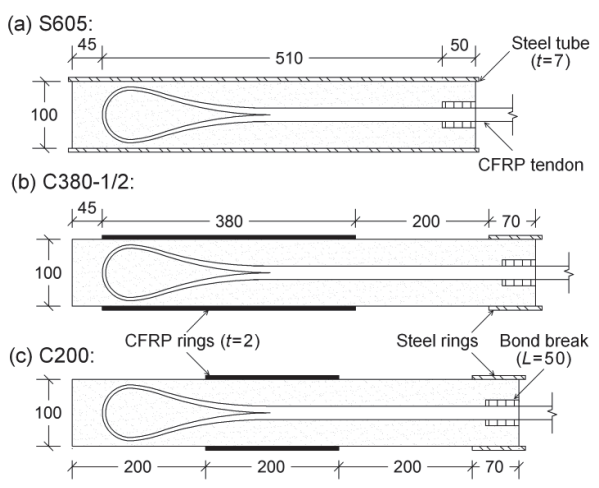

Fig. 3. Configuration of CFRP anchors (dimensions in $[\mathrm{mm}]$ )

Four anchor specimens with different configurations of the grouted part on the ground side, simulating the applications both in rock and soil, were investigated; an overview of the experimental series is shown in Table 1 and of the anchor configurations in Fig. 3. In experiment S605, a $7 \mathrm{~mm}$-thick and $605 \mathrm{~mm}$-long steel tube with an inner diameter of $100 \mathrm{~mm}$ was used to simulate the stiffness and confining pressure of a surrounding rock mass, as shown in Fig. 3 (a). For the applications in soil, the weak confinement provided by the surrounding soil mass was negligible and thus no steel tube was used. In this case, $2 \mathrm{~mm}$-thick CFRP confinement rings with an inner diameter of $100 \mathrm{~mm}$ were 
ECCM17 - $17^{\text {th }}$ European Conference on Composite Materials

installed around the grout-embedded strap end to improve the load-bearing capacity, as shown in Fig. 3 (b) and (c).

A non-shrink high-strength cement grout SikaGrout-212 (provided by Sika Schweiz AG, Switzerland) with a maximum aggregate size of $4 \mathrm{~mm}$ was used; the water/cement ratio was 0.12 . The three configurations of the whole anchor specimens are shown in Fig. 4. Configuration C380 was investigated twice to evaluate the repeatability of the results. After casting, the specimens were cured for 28 days under room temperature.

Table 1. Overview of experimental series and results.

\begin{tabular}{cccccc}
\hline Specimen & Confinement & $\begin{array}{c}\text { Confinement } \\
\text { length }(\mathrm{mm})\end{array}$ & $\begin{array}{c}\text { Confinement } \\
\text { thickness }(\mathrm{mm})\end{array}$ & $\begin{array}{c}\text { Ultimate } \\
\text { load }(\mathrm{kN})\end{array}$ & Failure mode \\
\hline S605 & Steel tube & 605 & 7 & 497 & strap rupture \\
C380-1 & CFRP ring & 380 & 2 & 529 & Grout compression \\
C380-2 & CFRP ring & 380 & 2 & 474 & Grout compression \\
C200 & CFRP ring & 200 & 2 & 256 & Grout splitting \\
\hline
\end{tabular}

\subsection{Experimental setup and instrumentation}

A self-balanced experimental set-up was designed for the pull-out experiments, as shown in Fig. 5 (a). The load was transferred from two identical hollow-plunger hydraulic cylinders of $576 \mathrm{kN}$ capacity to the upper strap end through a steel frame, while the vertical movement of the anchor body was blocked by steel plates under the cylinders. In experiment S605, the loading was manually applied in load-control mode at a rate of $15 \mathrm{kN} / \mathrm{min}$. In the other experiments, the loading was controlled by a digital multi-Channel control system Walter+Bai PCS 8000; one of the hydraulic cylinders was in displacement-control mode at a rate of $0.3 \mathrm{~mm} / \mathrm{min}$, while an identical load pressure was applied to the other cylinder. Five load cycles up to $25,50,100,150$ and $200 \mathrm{kN}$ respectively were applied in anchors C380-1 and C380-2 before the failure cycle. Only the first three of them were applied in S605 and the first two in $\mathrm{C} 200$ due to the lower expected capacity.

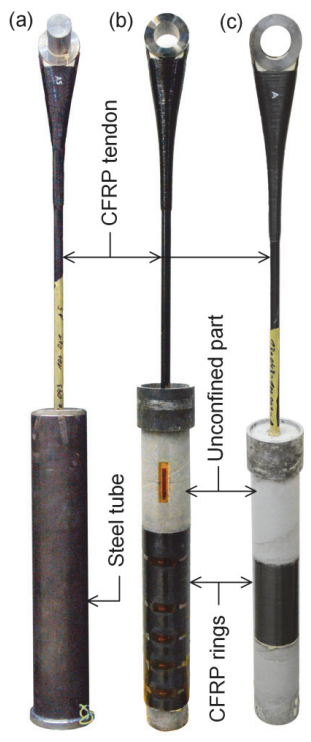

Fig. 4. Anchor specimens: (a) S605; (b) $\mathrm{C} 380-1$; (c) $\mathrm{C} 200$
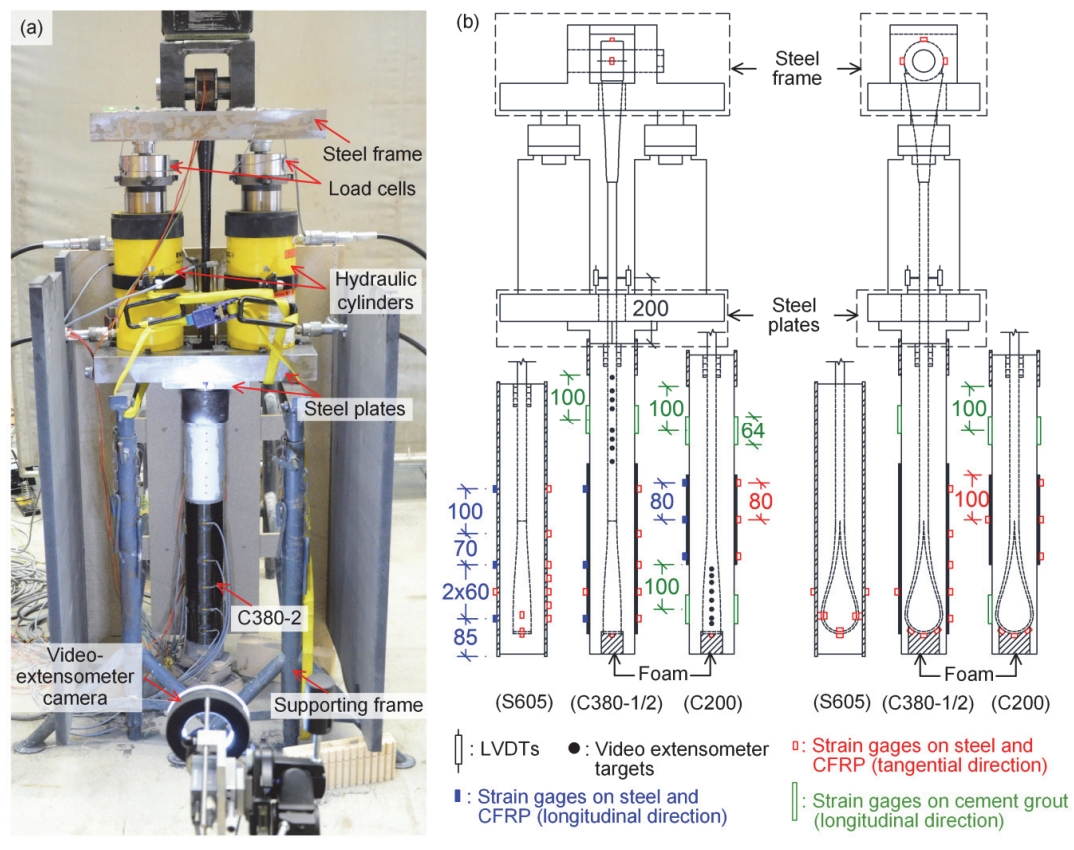

Fig. 5. Experimental set-up and instrumentation layout (dimensions in [mm]) 
The instrumentation layout is shown in Fig. 5 (b). The loads in the two hydraulic cylinders were measured by two load cells located between the cylinders and the steel frame. Three types of instruments were used: Linear Variable Differential Transformer (LVDT) transducers, strain gages and video extensometers. In the first experiment (S605), three axial gages were installed on both inner and outer sides of the embedded strap (see Fig. 5 (b)). In order to protect these gages during grout casting and curing, a combined layer of $2 \mathrm{~mm}$-thick silicon and $3.05 \mathrm{~mm}$-thick ABM $75(0.05 \mathrm{~mm}$ thick aluminum foil coated with $3 \mathrm{~mm}$-thick kneading compound) was applied on the gage surfaces. These thick layers interrupted the contact between the strap and grout on the inner side, leading to local bending of the strap. In the experimental results shown later, this local bending effect was eliminated by averaging the measurements of the opposite gages at the same location. In the other experiments, only three gages on the outer surface of the strap were installed.

\section{Results and discussion}

\subsection{Load vs. pull-out displacement responses and failure modes}

All anchors exhibited similar load vs pull-out displacement responses in the failure cycle, as shown in Fig. 6; the load cycles of anchor C380-1 are shown in the window of Fig. 6. A linear response was mainly observed, except the minor nonlinear behaviors at the beginning in all the specimens and at the end close to the ultimate load in the partially confined anchors. Furthermore, no stiffness degradation was observed between the cycles.

The obtained ultimate loads, $F_{u}$, and observed failure modes are listed in Table 1. Anchor S605 exhibited strap rupture, as shown in Fig. 7, while compression failure (C380-1 and C380-2, see Fig. 8) and splitting failure (C200, see Fig. 9) of the unconfined grout occurred in the partially confined cases. In the strap rupture case, the failure was located at the position of one inner strain gage, where the CFRP/grout interface was interrupted by the thick protection layer, as mentioned before (see Fig. 7 (b)).

In the grout failure cases (anchors C380-1 and C380-2), a double-cone failure mode was observed in the unconfined part, as shown in Fig. 8 (a), which resembled the one in the uniaxial compression experiments (see Fig. 8 (b)). The embedded straps remained undamaged. In contrast, anchor C200, where the strap was only partially confined, exhibited a 46.0/51.6\% lower ultimate load compared to C380-1/2. A vertical crack in the unconfined grout around the strap was observed at around $250 \mathrm{kN}$ load due to tensile stresses in the radial direction (which could not be balanced by a confinement ring at this location), leading to a final splitting failure, while the grout inside the strap remained undamaged, as shown in Fig. 9. It could be concluded that the length and position of the CFRP ring had a significant influence on the load-bearing capacity of the partially confined anchors. The loadbearing capacity of these anchors mainly depended on the uniaxial compressive strength of the unconfined grout outside the strap region, if the CFRP confinement ring was installed at an optimized position to balance the spreading forces from the strap.

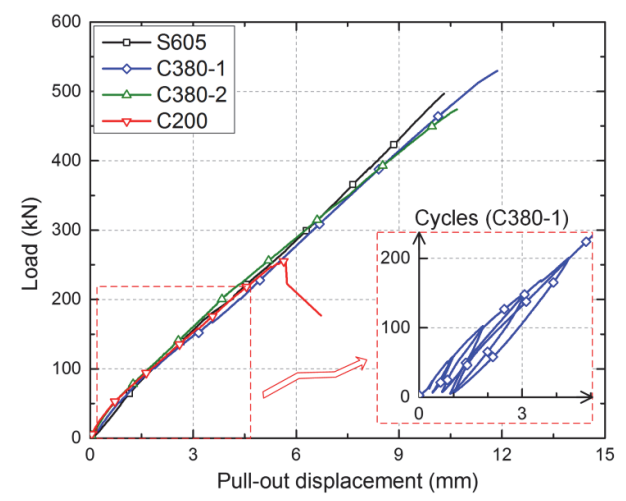

Fig. 6. Load vs pull-out displacement responses 


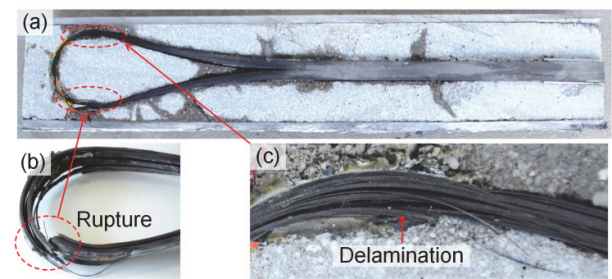

Fig. 7. Failure mode of anchor S605: (a) cut view of anchor body; (b) rupture of embedded strap at gage location; (c) strap delamination at gage location

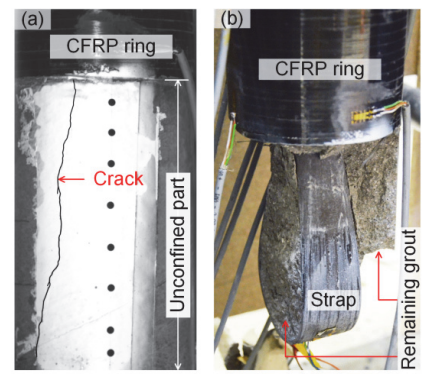

Fig. 9. Failure mode of anchor C200: (a) vertical grout crack at around $250 \mathrm{kN}$ load; (b) splitting failure of unconfined grout around embedded strap

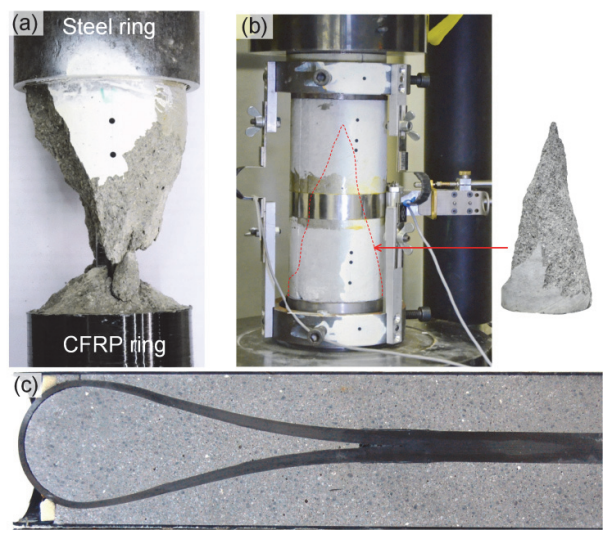

Fig. 8. Failure mode of anchor C380-2: (a) double-cone failure of unconfined grout; (b) similar failure mode in uniaxial compression experiment; (c) undamaged strap in confined part

\subsection{Tangential tensile strains in CFRP tendons and CFRP rings}

The load vs tangential tensile strains of the upper (air-side) straps are shown in Fig. 10. The straps exhibited linear behavior until failure and no stiffness loss was observed during the cycles.

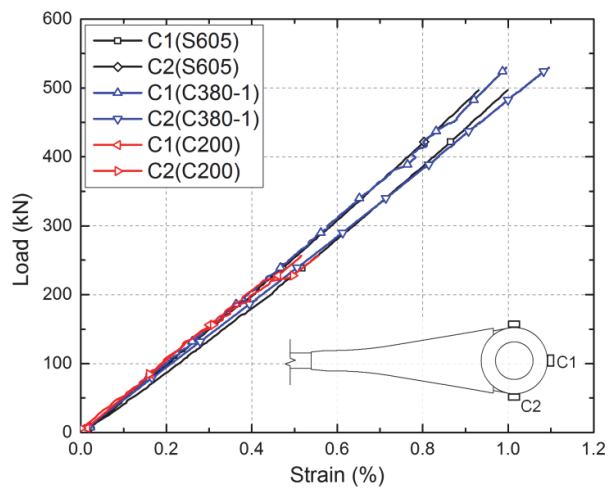

Fig. 10. Load vs tangential tensile strain responses of air-side straps

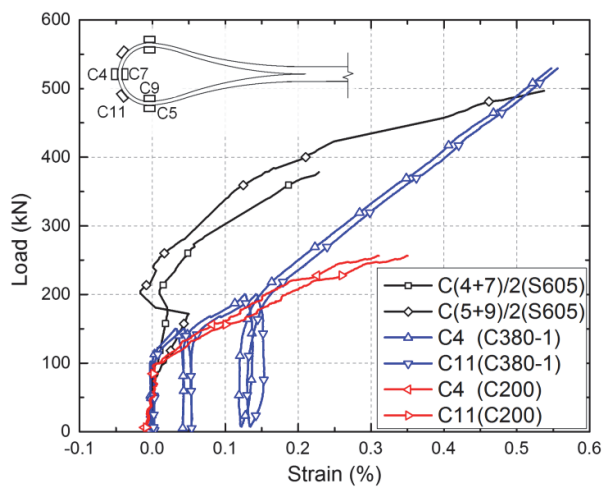

Fig. 11. Load vs tangential tensile strain responses of embedded straps

The load vs tangential tensile strain responses of the embedded straps are shown in Fig. 11; in anchor S605, the average strain values of the two opposite sides, at the same location on the strap, were considered (as mentioned above). In all the anchors, the load transfer to the embedded strap was delayed and occurred between $100-200 \mathrm{kN}$ load, due to the bond and friction at CFRP/grout interface, and the transition from the rod to the flat and curved strap geometry, which already transferred part of the load to the grout through transverse compression (i.e. the spreading forces). The friction also depended on the confinement level, i.e. the higher the confinement was, the later the strap was activated due to the higher friction. These mechanisms decreased the maximum strains at the ultimate loads at the embedded strap ends compared to the air-side ones. The loads transferred to the strap ends 
ECCM17 - $17^{\text {th }}$ European Conference on Composite Materials

Munich, Germany, 26-30 ${ }^{\text {th }}$ June 2016

in anchor S605 and C380-1 at failure, calculated based on the measured strains $(0.54$ and $0.56 \%$ respectively), were 247 and $255 \mathrm{kN}$, corresponding to only 49.6 and $48.2 \%$ of their ultimate loads respectively. Furthermore, recovery of the strap strains during unloading was prevented by the friction behavior as well. The strains thus remained at the same level during the unloading and reloading cycles (see Fig. 11).

\section{Conclusions}

Pull-out experiments were performed on four CFRP ground anchors with single-strap ends. To simulate applications in a rock mass, a steel tube was used to exert the confinement pressure of the rock mass on the grout cylinder of the anchor. In a soil mass, however, where significant confinement cannot be expected; the anchors were confined with CFRP rings, which were installed around the grout-embedded strap end at different positions and lengths. The following conclusions were drawn:

1. In rock applications, the anchor can be applied directly without additional confinement, while in the case of soil, an additional CFRP confinement ring is needed to prevent premature failure in the strap region.

2. With optimized location and length of the CFRP ring the anchor capacity is only limited by the uniaxial compressive strength of the unconfined grout cylinder at the transition to the free anchor length.

3. The load is transferred progressively from the strap to the grout cylinder: approximately $50 \%$ of the load is transferred at the semicircular strap end while the remaining $50 \%$ are transferred at the CFRP/grout interface and curved transition part from the flat strap to the circular rod geometry. The embedded strap is thus much less loaded than the air-side strap.

In a next step, a CFRP ground anchor with multi-strap ends will be investigated to achieve a loadbearing capacity of more than $1000 \mathrm{kN}$. Pull-out experiments will be conducted to verify the design and also to study the load-bearing behavior of the anchor.

\section{Acknowledgments}

The authors wish to acknowledge the support and funding of this research by the Swiss Federal Commission for Technology and Innovation CTI (Grant No. KTI 14139.2 PFIW-IWF) and the industry partners F.J. Aschwanden AG in Lyss, Carbo-Link AG in Fehraltorf (supplier of the CFRP tendon specimens), and Sika Schweiz AG in Zürich, Switzerland (supplier of the cement grout).

\section{References}

[1] P.P. Xanthakos. Ground anchors and anchored structures. John Wiley \& Sons, 1991.

[2] K. Aoyagi, T. Yoshida, Y. Yamazai, K. Maruyama. NM (new material) ground anchor system. Proceedings of the 2nd international conference on advanced composite materials in bridges and structures ACMBS II, Montreal, Canada, August 11-14 1996.

[3] J.W. Schmidt, A. Bennitz, B. Täljsten, P. Goltermann, H. Pedersen. Mechanical anchorage of FRP tendons-A literature review. Construction and Building Materials, 32:110-21, 2012.

[4] A.U. Winistoerfer. Development of non-laminated advanced composite straps for civil engineering applications. University of Warwick, 1999.

[5] H. Fan, A.P. Vassilopoulos, T. Keller. Experimental and numerical investigation of tensile behavior of non-laminated CFRP straps. Composites Part B: Engineering, 91:327-36, 2016.

[6] T. Keller, A. Kenel, R. Koppitz. Carbon Fiber-Reinforced Polymer Punching Reinforcement and Strengthening of Concrete Flat Slabs. ACI Structural Journal, 110(06), 2013.

[7] U, Huster, R, Broennimann, A, Winistörfer. Strengthening of a historical roof structure with CFRP-straps. Proceedings of the 4th international conference on FRP composites in civil engineering CICE2008. Zurich, Switzerland, July 22-24 2008.

[8] T.C. Triantafillou, M.N. Fardis. Strengthening of historic masonry structures with composite materials. Materials and Structures. 30(8):486-96, 1997. 